Hydrol. Earth Syst. Sci., 18, 1561-1573, 2014

www.hydrol-earth-syst-sci.net/18/1561/2014/

doi:10.5194/hess-18-1561-2014

(C) Author(s) 2014. CC Attribution 3.0 License.

\title{
Selection of intense rainfall events based on intensity thresholds and lightning data in Switzerland
}

\author{
L. Gaál ${ }^{1,2, *}$, P. Molnar ${ }^{1}$, and J. Szolgay ${ }^{2}$ \\ ${ }^{1}$ Institute of Environmental Engineering, ETH Zurich, Zurich, Switzerland \\ ${ }^{2}$ Slovak University of Technology, Bratislava, Slovakia \\ *now at: Technical University of Vienna, Vienna, Austria
}

Correspondence to: P. Molnar (molnar@ifu.baug.ethz.ch)

Received: 13 December 2013 - Published in Hydrol. Earth Syst. Sci. Discuss.: 14 January 2014

Revised: - Accepted: 12 March 2014 - Published: 6 May 2014

\begin{abstract}
This paper presents a method to identify intense warm season storms with convective character based on intensity thresholds and the presence of lightning, and analyzes their statistical properties. Long records of precipitation and lightning data at 4 stations and 10 min resolution in different climatological regions in Switzerland are used. Our premise is that thunderstorms associated with lightning generate bursts of high rainfall intensity. We divided all recorded storms into those accompanied by lightning and those without lightning and found the threshold $I^{*}$ that separates intense events based on peak 10 min intensity $I_{\mathrm{p}} \geq I^{*}$ for a chosen misclassification rate $\alpha$. The performance and robustness of the selection method was tested by investigating the inter-annual variability of $I^{*}$ and its relation to the frequency of lightning strikes. The probability distributions of the main storm properties (rainfall depth $R$, event duration $D$, average storm intensity $I_{\mathrm{a}}$ and peak $10 \mathrm{~min}$ intensity $I_{\mathrm{p}}$ ) for the intense storm subsets show that the event average and peak intensities are significantly different between the stations. Nonparametric correlations between the main storm properties were estimated for intense storms and all storms including stratiform rain. The differences in the correlations between storm subsets are greater than those between stations, which indicates that care must be exercised not to mix events of different origin when they are sampled for multivariate analysis, for example, copula fitting to rainfall data.
\end{abstract}

\section{Introduction}

Rainfall is one of main causes of natural hazards in hydrological systems (e.g. Vörösmarty et al., 2013; Wilhelmi and Morrs, 2013; Kyselý et al., 2013) and is inseparably related to flood risk (e.g. Hlavcova et al., 2005; Blöschl, 2008; Borga et al., 2011; Winsemius et al., 2013). Storms associated with high rainfall intensities often lead to severe flooding in catchments and urban areas, accelerated hillslope and channel erosion, triggering of landslides, mud and debris flows (e.g. Llasat, 2009; Brunetti et al., 2010; Badoux et al., 2012). The severity of storms and their damage potential is dependent not only on the total rainfall amount but also on other storm characteristics such as peak rainfall intensity and event duration. The statistical properties of these storm characteristics and their inter-dependencies are fundamental descriptors of intense storms for both practical (design) and scientific purposes.

The first question we address in this paper is how to select intense storms out of all events based on some common property. A good example is the distinction of precipitation into convective and stratiform rain which captures two different cloud dynamical processes (e.g. Houze, 1997). Convective rain is associated with higher rainfall intensities and is commonly identified from ground synoptic observations of clouds, state of weather and/or rain intensity fluctuations (e.g. Pešice et al., 2003; Chvila et al., 2005; Tremblay, 2005; Llasat et al., 2007; Berg et al., 2013; Ruiz-Leo et al., 2013; Rulfová and Kyselý, 2013). Weather radar provides additional information (e.g. updraft velocities and cloud water content), which aid the identification of convective rain (e.g. 
Rigo and Llasat, 2004, 2007; Llasat et al., 2005). Although formal convective-stratiform separation techniques (see comparison in Lang et al., 2003) are inherently limited because they do not directly quantify the origin and type of convection (Zimmer et al., 2011), they have one thing in common - that a locally high rainfall intensity is expected in events where convection is present even if embedded in stratiform systems. It is this extremity of rainfall intensity during a storm which we would like to capture in our selection of intense events, regardless of their exact meteorological origin and genesis.

The second question we address in this paper is how to define a threshold intensity for the identification of intense storms. This choice is rather arbitrary and depends on the time resolution used, that is, the duration for which the intensity exceeds the threshold (e.g. Llasat, 2001). There are very few objective methods to estimate the threshold intensity; one notable exception is Tremblay (2005) who partitions rain into stratiform and convective components with the latter being anomalies in the relation between total precipitation and precipitation intensity (e.g. Ruiz-Leo et al., 2013). This method is based on a global classification from raingauges and provides time dependent but not station-specific thresholds. It was developed for $6 \mathrm{~h}$ aggregations which are not always sufficient to capture short-term variations in rain intensity during convective storms.

One of the main goals in this paper is to develop a stationbased method to choose the intensity threshold based on long records of lightning strike data and precipitation measured at a high resolution $(10 \mathrm{~min})$. The premise is that summer thunderstorms with convective activity are commonly associated with lightning (e.g. Tapia et al., 1998; Rivas Soriano et al., 2001; Rivas Soriano and De Pablo, 2003; Barnolas et al., 2008; Tadesse and Anagnostou, 2009; Yair et al., 2010; Koutroulis et al., 2012). A number of recent studies have demonstrated the connection between intra-cloud and cloudto-ground lightning and convective precipitation using rainfall yield (i.e. the amount of rain per lightning flash), as a measure (e.g. Petersen and Rutledge, 1998; Grungle and Krider, 2006; Price and Federmesser, 2006; Pineda et al., 2007; Kochtubajda et al., 2013). Tapia et al. (1998) developed a model to predict the space-time distribution of rainfall as a function of rainfall yield and lightning strikes. However, the predictive strength of lightning count as an explanatory variable on a regional scale in these studies is not very strong.

The approach we take instead is that the simple presence of lightning in the vicinity of a raingauge is indicating the existence of convective activity. We find the rainfall intensity threshold that gives us an acceptable separation error between events accompanied by lightning and those that are not, and study their statistical properties. Although we use accurate station-based lightning data, the same approach applies to lightning data from long-range lightning detection ground networks or satellites (e.g. Defer et al., 2005; Price and Federmesser, 2006; Kotroni and Lagouvardos, 2008).
Our study complements other recent efforts focused on using lightning observations to better understand and predict convective storms and their consequences, for example, flash floods (Price et al., 2011a, b; Koutroulis et al., 2012).

The main contributions of this paper are threefold: (a) we provide a new method to identify intense warm season rainfall events as those in which the maximum intensity exceeds a threshold by using lightning strike data as an explanatory variable. We analyze the performance and robustness of this method by investigating the relations between the estimated threshold and lightning statistics. (b) We show the probability distributions of main storm properties for the intense storm subset identified by our method and discuss the differences between the studied stations. (c) We present nonparametric correlation coefficients between the main storm properties for the intense storm subset and contrast these with the correlations for all storms to highlight the particular interdependencies (or lack thereof) in intense storm properties. The analysis is conducted on four stations in different climatological regions in Switzerland and provides a basis for a follow-up regionalization effort.

\section{Data}

\subsection{Meteorological data and study sites}

The data used in this study are from stations of the SwissMetNet network (MeteoSwiss). These are automatic weather stations recording a range of hydroclimatic data at a $10 \mathrm{~min}$ sampling resolution. Our main data are precipitation and air temperature for the period 1981-2012 (32 years) and lightning strikes for the period 1987-2005 (19 years) at 62 stations with about $3000 \mathrm{~m}$ altitude difference (Fig. 1).

Precipitation is recorded by a heated tipping-bucket raingauge (Lambrecht) with orifice area $200 \mathrm{~cm}^{2}$ and tip resolution $0.1 \mathrm{~mm}$. The data are quality checked and corrected at the hourly resolution. The $10 \mathrm{~min}$ precipitation data have been analysed for their scaling-based properties (Molnar and Burlando, 2008) and short-term oscillations (Paschalis et al., 2012) and we are confident in their good quality. Air temperature is a standard measurement by a ventilated thermometer at $2 \mathrm{~m}$ height.

Four of the 62 stations are chosen as examples of different climatological regions in this paper (Fig. 1): Geneve-Cointrin (GVE, 420 ma.s.1.) in the lowland region north of the Alps, Napf (NAP, 1404 ma.s.l.) in the pre-Alpine region in central Switzerland, Scuol (SCU, 1304 ma.s.l.) in the Graubünden region in the east of Switzerland where substantial blocking of precipitation is observed, and Lugano (LUG, 273 ma.s.1.) in the Tessin region to the south of the main Alpine divide which is significantly affected by Mediterranean weather patterns and orographic forcing, especially in the summer and fall seasons (Panziera and Germann, 2010). 


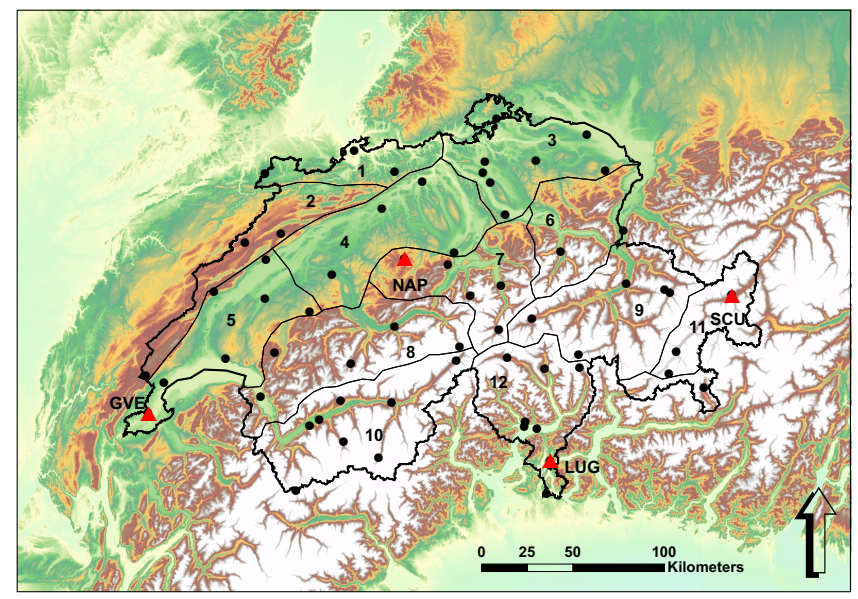

Fig. 1. The SwissMetNet stations in 12 climatic regions defined by Schüepp and Gensler (1980). The four selected stations in this paper are marked by red triangles: GVE - Geneve-Cointrin, NAP - Napf, SCU - Scuol, LUG - Lugano.

\subsection{Event definition}

Our analysis is based on precipitation events which we identify separately for the warm (April-September) and cold (October-March) half years, which we also call seasons in this paper. For the selection of potentially intense rainfall events, we limit ourselves to the warm season only and add a constraint that the air temperature during an event $T>4{ }^{\circ} \mathrm{C}$ to ensure liquid precipitation and minimise the likelihood of snow or mixed events at high altitude stations. In the determination of individual events, we disregarded all intervals with only 1 tip in $10 \mathrm{~min}(0.1 \mathrm{~mm} / 10 \mathrm{~min})$ because these are often artifacts of condensation and funnel drainage at the end of events and increase the duration of events with minimal increase in rainfall depth.

In practice it is common to define individual rainfall events by rainless intervals exceeding a selected duration called the inter-arrival time (also inter-event time, inter-storm period) $t_{\mathrm{i}}$ (Fig. 2). Many application-based criteria for identifying rainfall events using a fixed $t_{\mathrm{i}}$ have been presented in the literature, with values ranging from $3 \mathrm{~min}$ to $24 \mathrm{~h}$ (e.g. Dunkerley, 2008,2010 ). In our study we have chosen $t_{\mathrm{i}}=2 \mathrm{~h}$ based on the de-correlation time in the rainfall records (see next section for details).

For each event we determined four main event properties: total rainfall depth $(R)$, event duration $(D)$, average rainfall intensity $\left(I_{\mathrm{a}}=R / D\right)$, and peak (maximum) 10 min intensity during the event $\left(I_{\mathrm{p}}\right)$ (Fig. 2). Table 1 summarises the final number of events per warm season for the four stations, which ranged from an average of 84 ( 0.46 per day) at Scoul to 98 ( 0.54 per day) at Napf in the pre-Alpine area.

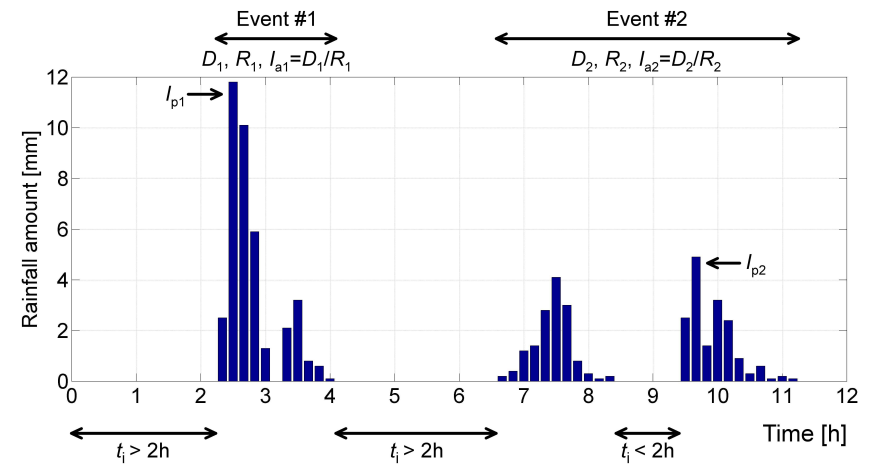

Fig. 2. A schematic to illustrate the identification of independent rainfall events (storms). Symbols: $D$ - event duration, $R$ - total rainfall depth, $I_{\mathrm{a}}$ - average rainfall intensity, $I_{\mathrm{p}}$ - peak $10 \mathrm{~min}$ intensity, $t_{\mathrm{i}}$ - inter-arrival time.

\subsection{Inter-arrival time}

An objective approach to choose $t_{\mathrm{i}}$ is to ensure that subsequent rainfall events are independent. Independence can be evaluated on a conceptual basis or statistically. The conceptual basis may for example be a model of the interception process which would identify independent events as those where $t_{\mathrm{i}}$ exceeds the timescale of evaporation from a fully saturated canopy (e.g. Lloyd, 1990; Zeng et al., 2000), or a time period during which soil wetness decreases sufficiently not to impact the subsequent flood runoff (e.g. Bracken et al., 2008). The statistical basis may for example be that $t_{\mathrm{i}}$ is sufficiently long for the autocorrelation in rainfall to become statistically insignificant (Grace and Eagleson, 1967), or the probability distribution of $t_{\mathrm{i}}$ closely exponential, like that of independent events in a Poisson process (Restrepo-Posada and Eagleson, 1982). Selecting long $t_{\mathrm{i}}$ may prove useful for ensuring the identification of statistically independent events, but in turn, it has a negative effect on storm properties by creating extensive intra-event gaps, leading to a strong bias in storm duration and average intensity (e.g. Restrepo-Posada and Eagleson, 1982; Dunkerley, 2010).

We chose a combination of conceptual and statistical considerations in identifying $t_{\mathrm{i}}$, bearing in mind that we want to preserve the extremal properties of intense rain events. Conceptually the values of $t_{\mathrm{i}}$ were a priori restricted to the order of the usual timescale of summer thunderstorms, and statistical independence of the events was ensured by analyzing the autocorrelogram of the sequences of $10 \mathrm{~min}$ rainfall. The lag at which the autocorrelation coefficient became statistically insignificantly different from zero for a chosen significance level indicates the inter-arrival time at which the storm events may be regarded as independent.

The autocorrelogram, that is, the Pearson correlation coefficient as a function of time lag, was determined for each station and each warm season separately. The autocorrelation 
Table 1. Main properties of the four selected SwissMetNet stations in this analysis: Geneve-Cointrin (GVE), Napf (NAP), Scuol (SCU) and Lugano (LUG). The storm statistics shown are for the warm season (April-September) with an additional constraint that air temperature $T>4{ }^{\circ} \mathrm{C}$ during an event.

\begin{tabular}{|c|c|c|c|c|}
\hline Station & GVE & NAP & SCU & LUG \\
\hline \multicolumn{5}{|l|}{ Station properties } \\
\hline Altitude [ma.s.1.] & 420 & 1404 & 1304 & 273 \\
\hline Mean annual precipitation (1961-1990) [mm] & 822 & 1736 & 693 & 1454 \\
\hline Climatological region (Schüepp and Gensler, 1980) & 5 & 4 & 11 & 12 \\
\hline \multicolumn{5}{|l|}{ Event statistics (1987-2005) } \\
\hline Mean number of events [noyr ${ }^{-1}$ ] & 88.7 & 98.0 & 84.0 & 94.9 \\
\hline Mean number of events with lightning [noyr ${ }^{-1}$ and $\%$ ] & $35.1(39.6)$ & $38.6(39.4)$ & $25.8(30.8)$ & $58.5(61.6)$ \\
\hline Threshold peak intensity $I^{*}\left[\mathrm{mmh}^{-1}\right]$ & 6.4 & 9.2 & 5.8 & 8.5 \\
\hline \multicolumn{5}{|l|}{ Storm characteristics (1981-2012) } \\
\hline Mean number of events $I_{\mathrm{p}}>I^{*}\left[\right.$ noyr $^{-1}$ and \%] & $24.6(28)$ & $26.8(28)$ & $19.6(24)$ & $34.3(37)$ \\
\hline Total rainfall depth, mean (stdev) [mm] & $11.1(10.5)$ & $14.8(14.2)$ & $9.8(8.7)$ & $21.1(21.3)$ \\
\hline Storm duration, mean (stdev) $[\mathrm{h}]$ & $3.7(3.9)$ & $4.1(4.3)$ & $3.6(3.4)$ & $4.6(5.4)$ \\
\hline Average storm intensity, mean (stdev) $\left[\mathrm{mmh}^{-1}\right]$ & $4.7(4.0)$ & $5.6(5.2)$ & $3.9(3.3)$ & $7.0(6.5)$ \\
\hline Peak 10 min intensity, mean (stdev) $\left[\mathrm{mmh}^{-1}\right]$ & $15.8(12.3)$ & $21.9(16.5)$ & $11.6(8.2)$ & $27.8(22.7)$ \\
\hline
\end{tabular}

functions for individual seasons were then averaged and are shown as dots in Fig. 3. The statistical significance was tested at the significance level $10 \%$. The de-correlation time ranged between 2 and $3 \mathrm{~h}$, and this was similar for the majority of the 62 SwissMetNet stations. Some mountain stations, such as Scuol in Fig. 3, show slightly longer de-correlation times. From this result we conclude that $t_{\mathrm{i}}=2 \mathrm{~h}$ gave us an appropriate de-correlation time in the rainfall records. Moreover it also matches the order of lifespan of thunderstorms in general.

\subsection{Lightning strikes}

Lightning-induced electric charge was measured locally at each SwissMetNet station by a ground antenna from 1987 to 2005 (19 years). After 2005 the data has been obtained under the Europe-wide EUCLID network (http://www.euclid.org) and extrapolated to the stations. To ensure homogeneity of the records we only consider the earlier period of local station measurements in this paper.

Lightning data are reported as the number of strikes within a certain range from the station at a $10 \mathrm{~min}$ time resolution. The sensitivity of the antenna allows an identification of close $(\lesssim 3 \mathrm{~km})$ and distant (between $\sim 3$ and $30 \mathrm{~km}$ ) lightning. Separation between cloud-to-ground and intra-cloud lightning is not possible. Figure 4 shows the most interesting statistics of lightning data at the Geneve station. Because this data has to our knowledge not yet been reported in the literature, we highlight the following main features which were common among all stations.

There are clearly many more distant strikes than close ones. However, their ratio remains rather stable across years.
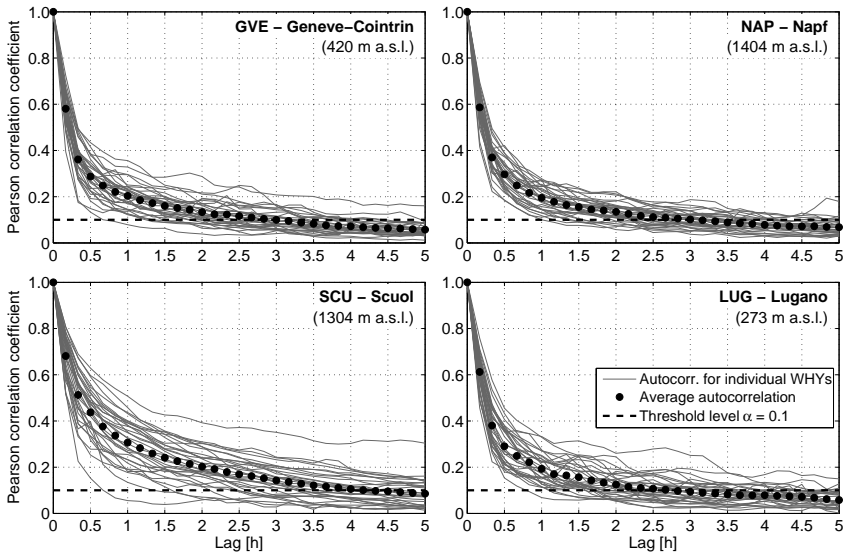

Fig. 3. Autocorrelograms for the selected four stations. Solid lines represent the autocorrelation coefficients for the individual warm half years (abbr. WHY) with lags of $10 \mathrm{~min}$. The dots show the average of the autocorrelation functions over all years. The dashed horizontal straight line is the critical correlation for the significance level $10 \%$.

The occurrence and actual sum of strikes in the cold (CHY) and warm (WHY) half years are dramatically different, with more than $90 \%$ of the strikes in the warm season indicating the connection between convectivity, ice build-up in cloud systems, electrification, and thunderstorm activity. The monthly distribution of lightning shows that the three most active months are June-July-August. The hourly distribution of lightning further indicates that lightning has a clear diurnal pattern with maxima between 15:00 and 18:00 UTC in the afternoon when convective activity is highest. There were some small differences at the Napf, Scuol and Lugano stations but 
the general tendencies were identical. Even if we do not take into account the actual count of lightning strikes, because this is a highly uncertain and site-dependent quantity, and only the presence or absence of lightning, the seasonal and diurnal statistics do not change appreciably.

Lightning data sheets like that in Fig. 4 for Geneve are available from the authors for all 62 stations of the SwissMetNet network.

\section{Method of intense storm event selection}

The method to select intense warm season storms out of our set of all storms is based on identifying events during which the peak $10 \mathrm{~min}$ intensity exceeds a threshold $I_{\mathrm{p}} \geq I^{*}$. This subset of intense storms can be assigned a convectivity index for every event $j$ as the fraction of the event total rainfall depth that falls with intensities greater than $I^{*}$ (Llasat, 2001):

$\beta_{j}=\frac{\int_{\tau=0}^{D_{j}}\left\{i ; i \geq I^{*}\right\} \mathrm{d} \tau}{R_{j}}$.

All events belonging to the set of intense events then have $0<\beta \leq 1$ and those that are not considered intense $\beta=0$.

Based on the findings that the occurrence of intense summer rainfall is indeed well correlated with lightning activity, especially over land (e.g. Petersen and Rutledge, 1998; Rivas Soriano et al., 2001; Rivas Soriano and De Pablo, 2003; Pineda et al., 2007; Barnolas et al., 2008; Tadesse and Anagnostou, 2009; Yair et al., 2010; Koutroulis et al., 2012), we propose to calibrate the threshold parameter $I^{*}$ at every station as a function of the presence or absence of lightning. In Sect. 3.1 we first analyze the storm properties for all events with and without lightning, and in Sect. 3.2 we then develop a statistical approach to estimate $I^{*}$ based on lightning data.

\subsection{Storm properties and lightning}

All storms in our data set were divided into those that were accompanied by lightning and those that were not. In this step we did not consider the actual count of lightning strikes but only the presence of lightning, similar to Katsanos et al. (2007) who used a fixed $6 \mathrm{~h}$ accumulation step for stations in the Mediterranean. We chose to include distant strikes as well as close strikes because we are defining a property of the events which is dependent on a larger scale propensity of the atmosphere around the station to generate extreme rainfall. In associating lightning with storm rainfall, we also considered strikes that occurred up to $20 \mathrm{~min}$ before the actual rainfall event began, which captures commonly observed time lags in pre-storm lightning-rainfall correlations (e.g. Grungle and Krider, 2006; Koutroulis et al., 2012).

We found that $31 \%$ (Scuol), $39 \%$ (Napf), $40 \%$ (Geneve), and $62 \%$ (Lugano) of the events were associated with lightning (Table 1). In this statistic Lugano was an exception and most stations in the SwissMetNet network had between 30
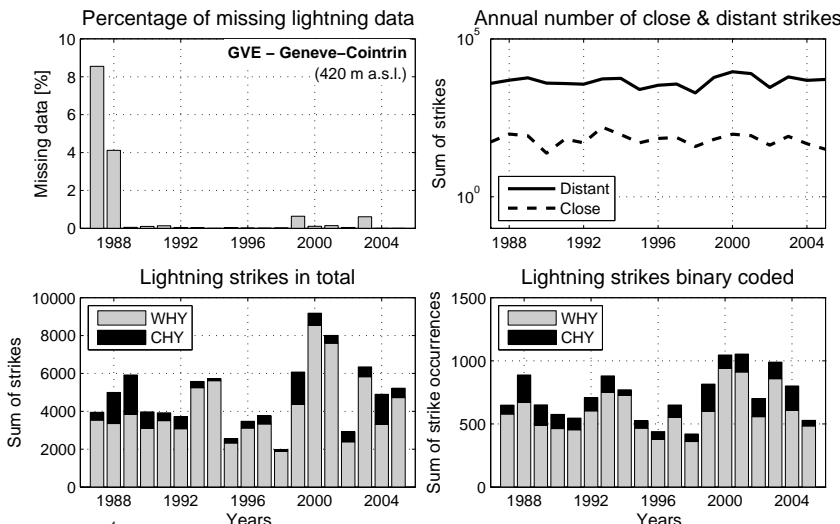

Lightning strikes binary coded
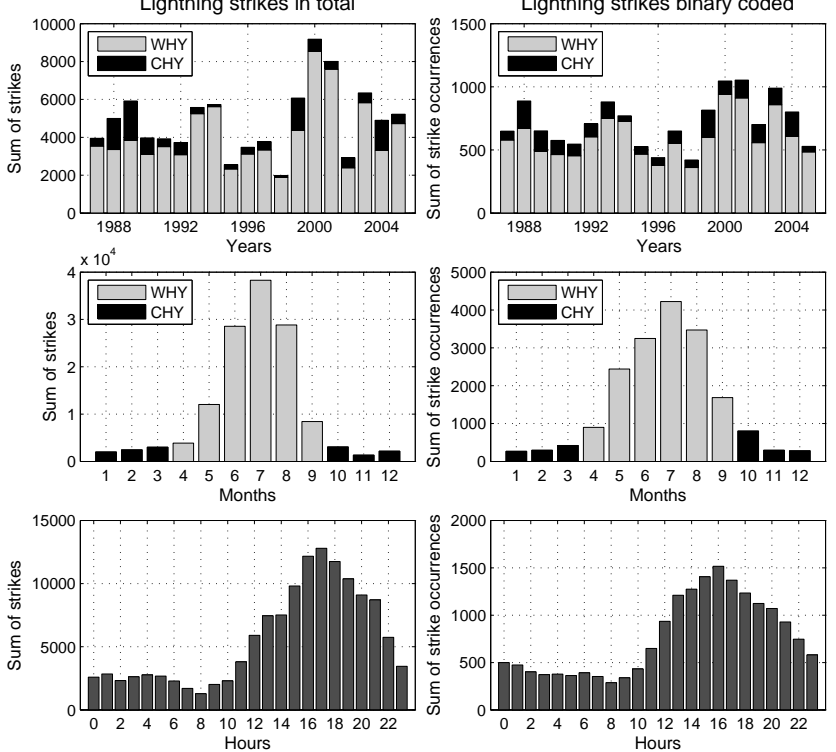

Fig. 4. Lightning data statistics for the station Geneve-Cointrin. Top left: percentage of missing (N/A) lightning data in each year. Top right: annual sums of close and distant lightning. The remaining figures show the distribution of all the observed lightning (regardless whether close or distant) from an annual (row 2), seasonal (row 3) and daily (row 4) perspective. Left panels show the actual number of lightning strikes, right panels show the sums of the lightning occurrence (binary per 10 min interval). WHY (CHY) stands for warm (cold) half year. Time is in UTC, which is $-2 \mathrm{~h} \mathrm{LT}$ (summer) and $-1 \mathrm{~h}$ LT (winter).

and $40 \%$ of storms with lightning in the warm half year on the average. Naturally stations at higher elevations and/or in valleys surrounded by mountain peaks have a higher proportion simply because lightning strikes are more frequent there.

Histograms of the four main rainfall event properties $(R$, $\left.D, I_{\mathrm{a}}, I_{\mathrm{p}}\right)$ were compared for the subsets of events with and without lightning for the period 1987-2005. The differences in the distributions were objectively assessed with statistical tests (Kolmogorov-Smirnov). Figure 5 shows the results for Geneve. The results were consistent for the other stations and show that rainfall duration $D$ and total rainfall depth $R$ are not statistically significantly related to the occurrence of lightning, except for very short durations and low rainfall totals. However, average rainfall intensity $I_{\mathrm{a}}$ and especially peak rainfall intensity $I_{\mathrm{p}}$ were consistently different for events accompanied by lighting.

The main difference in $I_{\mathrm{p}}$ was that events accompanied by lightning had higher peak intensities in general and the 

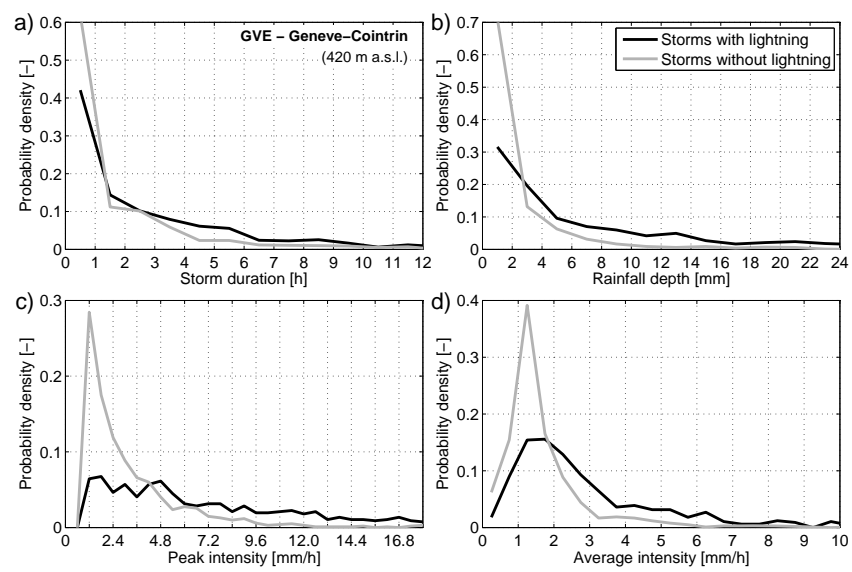

Fig. 5. Empirical probability density functions (PDFs) for the main storm properties: (a) storm duration $D$, (b) total rainfall depth $R$, (c) peak intensity $I_{\mathrm{p}}$, and (d) average storm intensity $I_{\mathrm{a}}$, differentiated by lightning, for station Geneve-Cointrin.

largest peak intensities were in fact observed only in storms with lightning. Also very low peak intensities were much more prevalent in storms without lightning. This result was true for all analyzed stations. We conclude that the short-term peak 10 min intensity $I_{\mathrm{p}}$ during an event is indeed the most useful variable to separate intense summer storm events of a mostly convective character from our event data set.

\subsection{Calibrating the intensity threshold}

The threshold intensity $I^{*}$ is an unknown parameter in our approach which selects intense storms of a mostly convective character out of all storms as those for which $I_{\mathrm{p}} \geq I^{*}$. This is our model under the assumption that lightning data is indicative of convective activity. We can then use the two subsets of storms with and without lightning for the calibration of the intensity threshold. For any $I^{*}$ we can compute the sensitivity, that is, the fraction of events accompanied by lightning which are identified as intense storms (true positives), and specificity, that is, the fraction of events not accompanied by lightning which are identified as not intense storms (true negatives). Plotting sensitivity versus specificity for a range of $I^{*}$ (see Fig. 6 for Geneve) gives us a complete indication of how good our model is because the departure of the data points from the diagonal indicates the power of the model to make a reliable selection (e.g. Begueria, 2006).

We choose an acceptable misclassification error $\alpha$ of no lightning events as convective (false positives, Type I error) to make a decision for $I^{*}$ as the threshold where specificity $=1-\alpha$. This decision is based on the argument that when lightning occurs in the vicinity of the gauge but we do not measure high intensity rain this could be caused by sampling the edge of a passing convective cell. While when lightning does not occur but we do measure high intensity rain this is indeed an error in our model which we would like to minimise. This error contains all the physical processes that may lead to intense precipitation in the absence of lightning (e.g. embedded convection in stratiform systems, low updraft velocities and ice build-up, etc). By choosing the same $\alpha$ for all stations, we have an objective way to compare the properties of the intense storms between stations. In this study we take $\alpha=0.1$, and the corresponding $I^{*}$ values are between 5.8 and $9.2 \mathrm{mmh}^{-1}$ at the four stations (Table 1).

\section{Results}

We present the results by first discussing the calibrated intensity thresholds $I^{*}$ with regard to some previous studies. We then analyze the performance of the method to select intense warm season rainfall events, and finally present the basic statistics of the main storm properties for this set of events and their cross-correlations.

\subsection{Comparison of intensity thresholds}

The calibrated thresholds to identify intense warm season storms with convective character at the four studied stations are lower than what is reported in most climatological and engineering hydrology literature for extreme convective rain. For example, Dutton and Dougherty (1979) and Watson et al. (1982) present a threshold of $48-50 \mathrm{mmh}^{-1}$ for considering rainfall to be all of convective origin. Llasat (2001) considers that convective rain events exceed a peak $5 \mathrm{~min}$ intensity of $35 \mathrm{~mm} \mathrm{~h}^{-1}$, and a threshold for average hourly intensities for heavy rainfall defined by the Spanish National Meteorological Institute is $15 \mathrm{mmh}^{-1}$. Earlier studies, like Wussow (1922) developed an empirical formula for Germany which gives $7.1 \mathrm{~mm}$ for strong rainfall of 10 min duration (i.e., $43 \mathrm{~mm} \mathrm{~h}^{-1}$ ), and Reinhold (1940) classified heavy rainfall when intensities for $10 \mathrm{~min}$ durations exceeded $40 \mathrm{~mm} \mathrm{~h}^{-1}$. Velikanov (1964) describes a classification where the threshold for $10 \mathrm{~min}$ intensive rainfall is given as $3.8 \mathrm{~mm}$, that is, $23 \mathrm{~mm} \mathrm{~h}^{-1}$. This classification was also used in former Czechoslovakia by Dub and Němec (1969). Dunkerley (2010) reports that in the context of erosion an event was only significant by Wischmeier and Smith (1978) if either the rain depth was larger than $12.5 \mathrm{~mm}$ or the rain rate exceeded $6.5 \mathrm{~mm}$ in $15 \mathrm{~min}$, that is, $26 \mathrm{~mm} \mathrm{~h}^{-1}$ (Kinnell, 2003).

A direct comparison of our thresholds with the above (and other) studies is not possible for several reasons. First is that these studies are generally focused at identifying very heavy convective rainfall events only, while we are interested in selecting a larger set of storms which are of convective character and not only the most extreme of them. Second is that many of these studies use different temporal resolutions of the rainfall data which strongly affects the threshold intensities (e.g. Llasat, 2001), and naturally the results vary considerably from one region to another based on the local climate. 

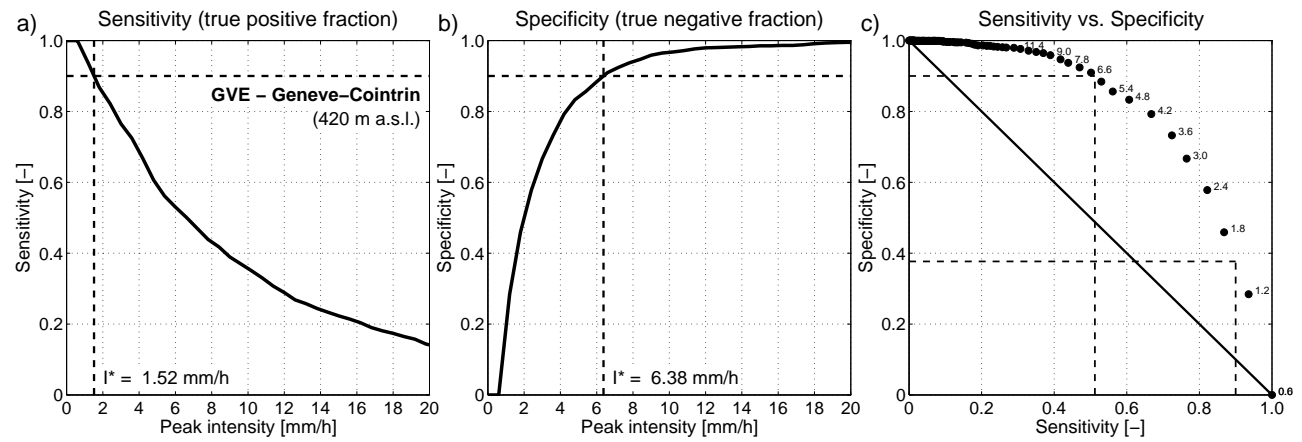

Fig. 6. Estimation of the threshold peak intensity $I^{*}$ on the basis of sensitivity (a) and specificity (b) at station Geneve-Cointrin. The plot (c) shows the inter-relation of sensitivity and specificity at the same station. The numbers within the plot indicate the corresponding value of peak intensity in $\mathrm{mmh}^{-1}$.

In our work it is the misclassification rate $\alpha$ which determines $I^{*}$. If we are stricter on the acceptable Type I error in our model (lower $\alpha$ ) then the threshold $I^{*}$ increases. However, this goes at the expense of increasing Type II error, that is, our model will have a lower sensitivity with respect to identifying events accompanied by lightning as convective (see Fig. 6).

\subsection{Testing the robustness of the method}

Because lightning data which are key in our method to estimate $I^{*}$ may vary strongly in time and space and be nonhomogeneous, a question to be answered is how robust the results are with respect to lightning variability. We examine two aspects: the inter-annual variability of $I^{*}$ and its relation to the frequency of lightning strikes.

Inter-annual variability in $I^{*}$ estimated on a bi-annual basis is shown together with the estimate for the entire 18 year record (until 2004) with reliable lightning data for all four stations in the left panel in Fig. 7. The result is that there is no evident trend in the estimate of $I^{*}$, although the local station inter-annual variability in lightning strikes, as seen for instance in Lugano, may lead to larger variability in the estimate. We also plot the corresponding bi-annual estimate of sensitivity in the right panel in Fig. 7. If lightning was not a predictor of intense events in our model, the sensitivity would be equal to the chosen misclassification rate $\alpha=0.1$. The results show that the sensitivity at all stations is in fact much greater than $\alpha$ and is in the range $\sim 0.4$ on the average. There is some inter-annual variability in model performance; however, it is not unacceptable. In fact, in Lugano the performance is practically constant, which is a good indication of the robustness of the connections between lightning and intense rain over time at this station.

The second aspect to test is whether $I^{*}$ is related to the frequency of lightning strikes and its variability from year to year. We would like to clarify if it is possible that the frequency of storms with lightning changes in time and thereby affects the estimate of $I^{*}$. The number of storms with and
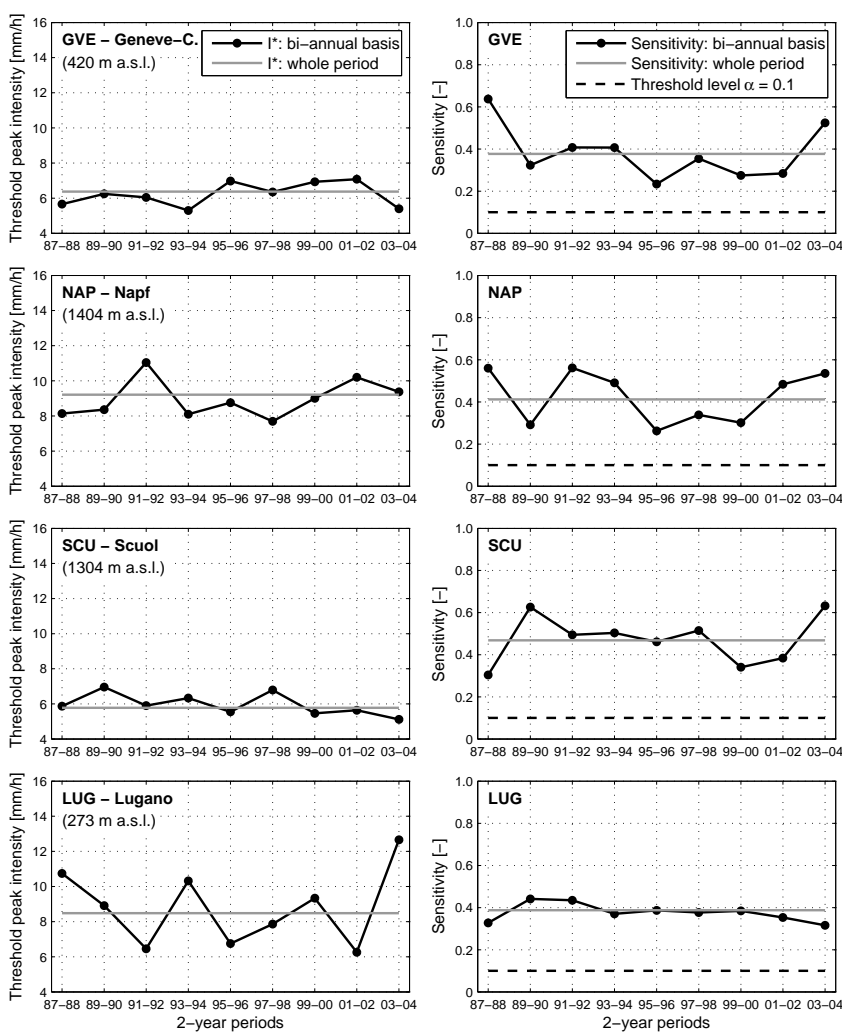

Fig. 7. Threshold peak intensity $I^{*}$ estimated on a bi-annual basis (left column) and the sensitivity corresponding to $I^{*}$ on a bi-annual basis (right column) at the studied stations. The dashed horizontal line on the right panels denotes the chosen misclassification error $\alpha=0.1$.

without lightning estimated on a bi-annual basis are shown in the left panel in Fig. 8. The proportion of storms with lightning remains reasonably consistent between years at all stations. More importantly, $I^{*}$ is clearly independent of the frequency of storms with lightning shown in the right panel in Fig. 8, which allows us to conclude that we have a robust method to extract intense storms from our data set based on 

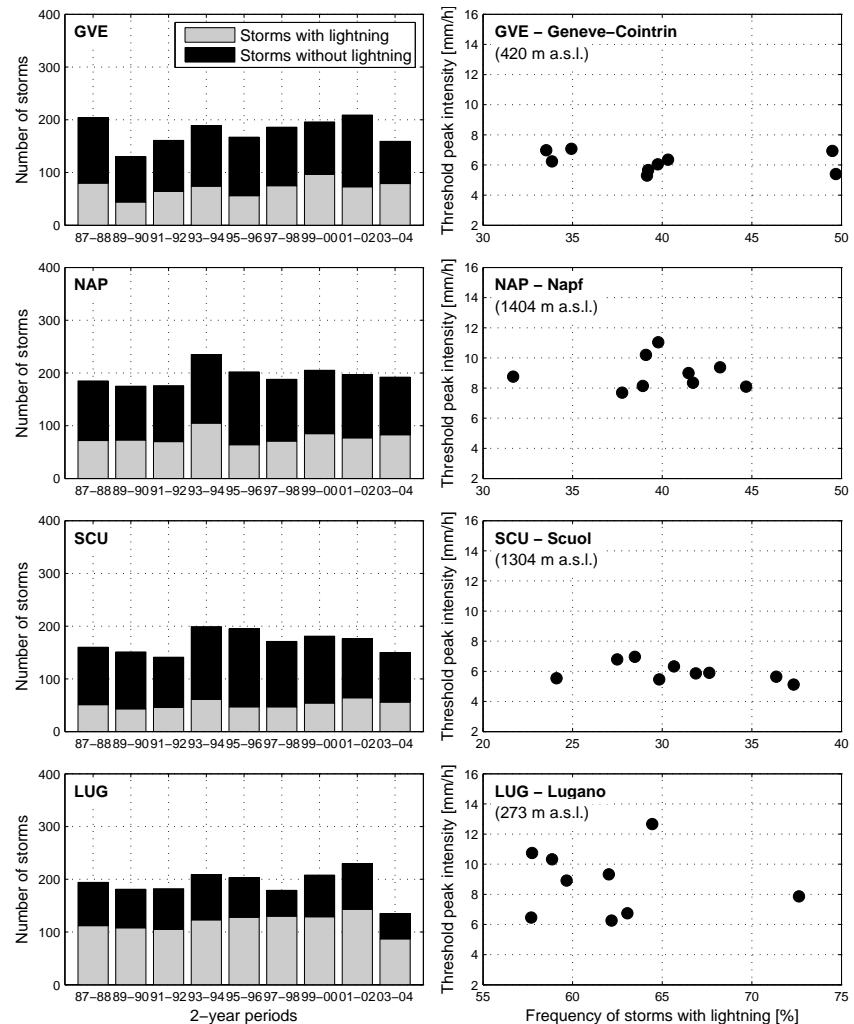

Fig. 8. Number of storms with and without lightning on a bi-annual basis (left column) and the relationship between threshold peak intensity $I^{*}$ and the frequency of storms with lightning on a bi-annual basis (right column) at the studied stations. Note the different scale of $x$ axes for the stations.

peak 10 min intensity alone, which at the same time coincide well with those which are accompanied by lightning.

\subsection{Properties of selected storms}

Because the subset of intense summer storms should mostly contain intensities associated with convective events, we use the convectivity index defined by Llasat (2001) in Eq. (1) to quantify the strength of convection on an event basis. The cumulative probability distributions of $\beta$ in Fig. 9 show an almost uniform shape at all stations. As expected, the highest convectivity overall was observed in Lugano in southern Switzerland. Llasat (2001) identified events with $\beta>0.8$ as strongly convective in Spain, which would correspond to $18 \%$ (Napf and Scuol), $20 \%$ (Geneve), and $30 \%$ (Lugano) of the events in our data set.

The cumulative distributions of the main storm properties of the events are shown in Fig. 10 and some basic statistics are listed in Table 1 . The exceedance probability is shown to accentuate the behaviour of extremes. The stations show a very similar distribution of storm duration, except for Lugano which has the longest events. Storm duration is not a variable that is very strongly affected by the different regional

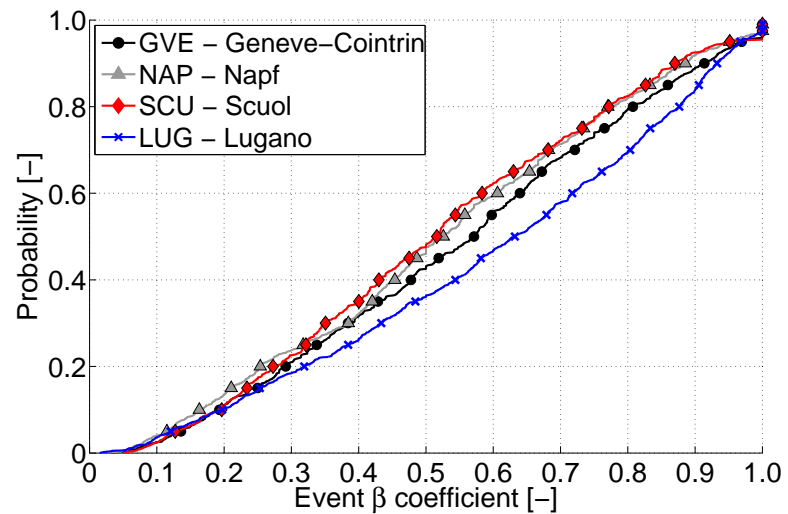

Fig. 9. Cumulative distributions (non-exceedance probability) of event $\beta$ coefficients for all the storms with $I_{\mathrm{p}} \geq I^{*}$ (i.e., $\beta>0$ ), for the studied stations.
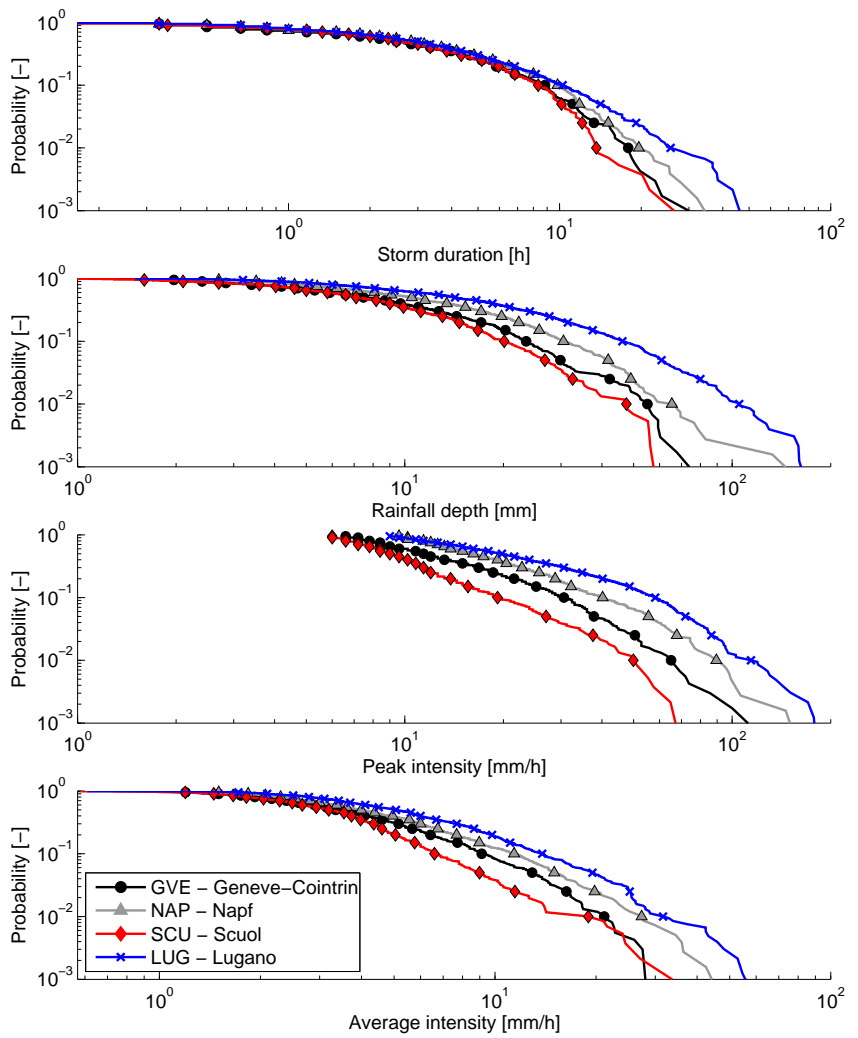

Fig. 10. Cumulative distributions (exceedance probability) of main storm properties for intense warm season storms: storm duration $D$, total rainfall depth $R$, peak intensity $I_{\mathrm{p}}$ and average storm intensity $I_{\mathrm{a}}$ (from top to bottom) at the studied stations.

climates; however, the other variables are statistically significantly different between the stations. Average event intensity is higher in Lugano than in the other stations, leading to the highest event rainfall depths; also, peak 10 min intensity during an event is highest in Lugano, followed by Napf and Geneve. Extremes are particularly affected. For example 
an event from our subset with a probability of exceedance of $20 \%$, that is an event that occurs about 5-6 times a year, has a peak $10 \mathrm{~min}$ intensity of about $40 \mathrm{mmh}^{-1}$ in Lugano, $25 \mathrm{mmh}^{-1}$ in Napf, and $20 \mathrm{mmh}^{-1}$ in Geneve.

One of our main aims was to quantify the correlations between main storm properties for the intense storm subset and contrast these with the correlations for all storms, to highlight the particular inter-dependencies (or lack thereof) in intense storm properties. We chose all storms instead of the subset of less intense storms since we would like to show the differences between our selection and a traditional choice where all storms are used regardless of their meteorological origin. To quantify the correlations, we use the Spearman rank correlation coefficient because we intend to use the relations between storm properties for statistical multivariate analysis with the method of copulas. Copula parameters depend on the correlations between the variables, which are generally quantified with a non-parametric correlation in the literature (e.g. Genest and Favre, 2007; Serinaldi, 2008; Vandenberghe et al., 2010).

The Spearman rank correlation coefficient estimated for all six pairs of variables and all stations is shown in Fig. 11. The results show that the intense summer storm events have practically no correlation between peak intensity $I_{\mathrm{p}}$ and the duration of the event $D$, while when all storms are considered including stratiform rain this correlation was significantly positive. Another interesting observation is that $I_{\mathrm{p}}$ is less strongly correlated to total rainfall depth $R$ in our intense storm subset than in all events. In other words, in events with intensities associated usually with convection, a high intensity over a short period of time does not necessarily lead to a high overall event total, while in events with stratiform rain rates that is generally the case. As expected, average storm intensity $I_{\mathrm{a}}$ is negatively correlated with duration $D$ in the convective intense event set but not for all storms.

Some of the correlation coefficients in the event sets are statistically significant (Fig. 11) and they suggest that a multivariate approach, for instance on the basis of copulas, is advised for probabilistic modelling of extreme storm properties (e.g. Kao and Govindaraju, 2007; Serinaldi, 2008; Bárdossy and Pegram, 2009; Vandenberghe et al., 2010). Overall the differences in the correlation coefficients between stations are much smaller than between the convective event set and the entire set of events, which means that it is of first order importance to select wisely the sample of intense events for multivariate analysis.

\section{Discussion of selection method and extremes}

The traditional approach to the analysis of extreme rainfall is the depth-duration-frequency (DDF) curve applied to annual maxima or peaks over a threshold (POT), where for a given duration, the most extreme rainfall depths (intensities) in a year are selected and their probability of occurrence is

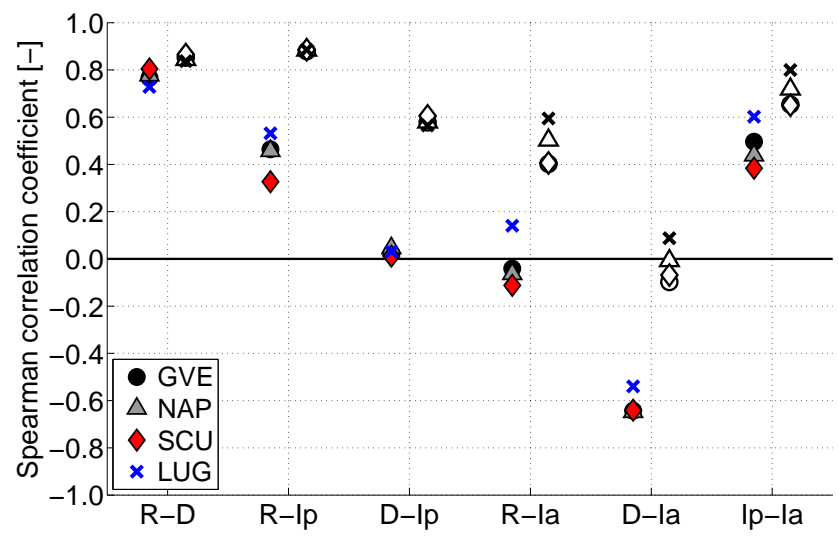

Fig. 11. Spearman rank correlation coefficients between pairs of main storm properties (storm duration $D$, total rainfall depth $R$, peak intensity $I_{\mathrm{p}}$ and average storm intensity $I_{\mathrm{a}}$ ) for intense warm season storms (filled, color markers) and all storms (empty markers) at the studied stations.

estimated. Estimation methods for the analysis of annual and POT extremes are well known and reported in the literature (e.g. Katz et al., 2002) as well as the mathematical framework for studying DDF curves (e.g. Koutsoyiannis et al., 1998). Estimation uncertainties are related to fitting an extreme value distribution to the selected data (mostly GEVtype) and functional forms for the DDF relation parameters, and these may be quantified from station as well as weather radar data (e.g. Overeem et al., 2008, 2009). The result is an estimated rainfall intensity for a given duration and return period. The threshold intensity comes from the minimum observed annual extreme in the record (annual maxima), or the choice of the average number of events per year (POT). Its basis is purely statistical - it is record period and duration dependent.

Our approach is different in two main ways: (1) we are looking at rainfall events as independent outcomes of atmospheric water vapour fluxes and precipitation formation processes. We do not fix a priori a given rainfall duration in the analysis (like in DDF curves) but we study several event properties and their statistics. (2) We select events which have a common physical origin and genesis (i.e. the presence of convection) insofar as it is reflected in a high peak 10 min intensity during the event. In this way we select many events, which are both short and long, with different rainfall totals, for the analysis, in contrast to only extreme intensities for DDF curves. Our threshold $I^{*}$ is calibrated with lightning data, which are independent measurements. To us this threshold has a physical meaning, as a short-term rain intensity which was exceeded in most convective rainfall events at a given station.

The consequence is that our threshold $I^{*}$ is not in fact directly comparable with POT or any other intense rainfall thresholds which are purpose driven. Most studies define subjective thresholds based on hydrological risk, monitoring 
issues, or meteorological considerations. Some of these are discussed in Sect. 4.1. At this point we can say that despite the fact that our thresholding is different from the DDF approach, the statistics of extremes in our selection of intense storms agree reasonably well with the HADES (Hydrological Atlas of Switzerland) estimates from DDF analysis, where the $1 \mathrm{~h}$ duration extremes with a return period $2.33 \mathrm{yr}$ ranged from 18 to $34 \mathrm{mmh}^{-1}$ at our four study sites (Jensen et al., 1997), while our selection gave peak 10 min rainfall intensities with a non-exceedance probability $p=0.8$ (i.e., the largest 5-6 events per year) between 20 and $40 \mathrm{mmh}^{-1}$. In a subsequent study, we will explore the full spatial distribution of event properties across all 62 stations in Switzerland.

\section{Conclusions}

Properties of intense storms, such as total rainfall depth, storm duration, average intensity and peak intensity are important descriptors of the rainfall regime at a site. For the statistical analysis of rainfall events and extremes it is often important that the storms in the analyzed sample have a common meteorological origin, for instance convective rain, stratiform rain, hail, snowfall, etc. A similar concept may also be found in catchment hydrology where on the basis of meteorological conditions and catchment state different flood types are defined (Merz and Blöschl, 2003) and statistically analyzed (e.g. Gaál et al., 2012). In this paper we took this common property of intense warm season storms to be the short-term $(10 \mathrm{~min})$ peak in rainfall intensity. It is this extremity of rainfall intensity during a storm which we would like to capture in our selection of intense events. We estimated the threshold intensity with the help of a unique lightning data set, thereby capturing the convective character of these intense events. The main conclusions of the paper are

1. We developed a new method to identify intense warm season rainfall events as those in which the peak 10 min intensity exceeds a threshold $I_{\mathrm{p}} \geq I^{*}$ by using lightning data as an external variable for the presence of convection. We divided all storms into those accompanied by lightning and those without lightning and found the threshold $I^{*}$ that separates intense events for a chosen misclassification rate $\alpha$. Altogether $31 \%$ (Scuol), $39 \%$ (Napf), $40 \%$ (Geneve), and $62 \%$ (Lugano) of the events were associated with lightning at our studied stations and the calibrated $I^{*}$ values are between 5.8 and $9.2 \mathrm{mmh}^{-1}$ at the four stations (Table 1).

2. The performance and robustness of the selection method was tested by investigating the inter-annual variability of $I^{*}$ and its relation to the frequency of lightning strikes. We found that there is no evident trend in the estimate of $I^{*}$ and the performance of the model in time. $I^{*}$ is independent of the absolute frequency of storms with lightning at all stations, which allows us to conclude that our method to extract intense storms, which at the same time coincide well with those which are accompanied by lightning and therefore have a convective character, is robust.

3. We analyzed the probability distributions of the main storm properties (rainfall depth $R$, event duration $D$, average intensity $I_{\mathrm{a}}$ and peak 10 min intensity $I_{\mathrm{p}}$ ) for the intense storm subset and found that while storm duration did not vary significantly between stations, the other properties did. Average event and peak intensity was much higher in Lugano in southern Switzerland, than in the other stations. The strength of convection measured by the convectivity index (Llasat, 2001) $\beta$ was also highest in Lugano where $30 \%$ of the events would be considered strongly convective.

4. We presented non-parametric correlation coefficients between the main storm properties for the intense storm subset and compared them with the correlations for all storms to highlight the particular interdependencies in intense storm properties. The results show that the intense warm season storm events have practically no correlation between peak intensity $I_{\mathrm{p}}$ and event duration $D, I_{\mathrm{p}}$ is less strongly correlated to total rainfall depth $R$, and average storm intensity $I_{\mathrm{a}}$ is more strongly negatively correlated with duration $D$ in our intense event set than for all events, including those of a stratiform nature. The differences in the correlations between storm subsets were significant and greater than those between stations, which indicates that care must be exercised not to mix events of different origin when they are sampled for multivariate analysis, e.g. copula fitting to rainfall data.

The analysis in this paper was reported for four representative stations in different climatological regions in Switzerland to illustrate the selection methodology. In a followup effort we will extend the analysis to all 62 stations of the SwissMetNet network and develop regionalization approaches which will allow the estimation of spatially distributed $I^{*}$ in Switzerland to be used where lightning data are not available.

Acknowledgements. This research was funded by the Scientific Exchange Program (Sciex-NMS) grant 11.034 and the Marie Curie Intra European Fellowship (FP7-PEOPLE-2011-IEF) grant 301953 IMPALA, both awarded to the first author. LG and JS also acknowledge the support of the Slovak Research and Development Agency grant APVV-0303-11 and VEGA Agency grant 1/0908/11. MeteoSwiss provided the hydroclimatic data. Comments and suggestions of two anonymous reviewers substantially improved the paper. 
Edited by: T. Kjeldsen

\section{References}

Badoux, A., Turowski, J. M., Mao, L., Mathys, N., and Rickenmann, D.: Rainfall intensity-duration thresholds for bedload transport initiation in small Alpine watersheds, Nat. Hazards Earth Syst. Sci., 12, 3091-3108, doi:10.5194/nhess-12-30912012, 2012.

Bárdossy, A. and Pegram, G. G. S.: Copula based multisite model for daily precipitation simulation, Hydrol. Earth Syst. Sci., 13, 2299-2314, doi:10.5194/hess-13-2299-2009, 2009.

Barnolas, M., Atencia, A., Llasat, M. C., and Rigo, T.: Characterization of a Mediterranean flash flood event using rain gauges, radar, GIS and lightning data, Adv. Geosci., 17, 35-41, doi:10.5194/adgeo-17-35-2008, 2008.

Begueria, S.: Validation and evaluation of predictive models in hazard assessment and risk management, Nat. Hazards, 37, 315329, doi:10.1007/s11069-005-5182-6, 2006.

Berg, P., Moseley, C., and Haerter, J. O.: Strong increase in convective precipitation in response to higher temperatures, Nat. Geosci., 6, 181-185, doi:10.1038/NGEO1731, 2013.

Blöschl, G.: Flood warning - on the value of local information, International Journal of River Basin Management, 6, 41-50, doi:10.1080/15715124.2008.9635336, 2008.

Borga, M., Anagnostou, E. N., Blöschl, G., and Creutin, J.D.: Flash flood forecasting, warning and risk management: the HYDRATE project, Environ. Sci. Policy, 14, 834-844, doi:10.1016/j.envsci.2011.05.017, 2011.

Bracken, L. J., Cox, N. J., and Shannon, J.: The relationship between rainfall inputs and flood generation in south-east Spain, Hydrol. Process., 22, 683-696, doi:10.1002/hyp.6641, 2008.

Brunetti, M. T., Peruccacci, S., Rossi, M., Luciani, S., Valigi, D., and Guzzetti, F.: Rainfall thresholds for the possible occurrence of landslides in Italy, Nat. Hazards Earth Syst. Sci., 10, 447-458, doi:10.5194/nhess-10-447-2010, 2010.

Chvila, B., Sevruk, B., and Ondras, M.: The wind-induced loss of thunderstorm precipitation measurements, Atmos. Res., 77, 2938, doi:10.1016/j.atmosres.2004.11.032, 2005.

Defer, E., Lagouvardos, K., and Kotroni, V.: Lightning activity in the eastern Mediterranean region, J. Geophys. Res., 110, D24210, doi:10.1029/2004JD005710, 2005.

Dub, O. and Němec, J.: Hydrologie, Technický průvodce, SNTL, Prague, 380 pp., 1969.

Dunkerley, D. L.: Rain event properties in nature and in rainfall simulation experiments: a comparative review with recommendations for increasingly systematic study and reporting, Hydrol. Process., 22, 4415-4435, doi:10.1002/hyp.7045, 2008.

Dunkerley, D. L.: How do the rain rates of sub-event intervals such as the maximum 5- and 15 -min rates $\left(I_{5}\right.$ or $\left.I_{30}\right)$ relate to the properties of the enclosing rainfall event?, Hydrol. Process., 24, 2425-2439, doi:10.1002/hyp.7650, 2010.

Dutton, E. J. and Dougherty, H. T.: Year-to-year variability of rainfall for microwave applications in the USA, IEEE T. Commun., 5, 829-832, doi:10.1109/TCOM.1979.1094464, 1979.
Gaál, L., Szolgay, J., Kohnová, S., Parajka, J., Merz, R., Viglione, A., and Blöschl, G.: Flood timescales: Understanding the interplay of climate and catchment processes through comparative hydrology, Water Resour. Res., 48, W04511, doi:10.1029/2011WR011509, 2012.

Grace, R. A. and Eagleson, P. S.: A model for generating synthetic sequences of short-time-interval rainfall depths, in: Proceedings of International Hydrology Symposium, Fort Collins, Colorado, USA, 268-276, 1967.

Genest, Ch. and Favre, A.-C.: Everything you always wanted to know about copula modeling but were afraid to ask, J. Hydrol. Eng., 12, 347-368, doi:10.1061/(ASCE)10840699(2007)12:4(347), 2007.

Grungle, B. and Krider, P.: Cloud-to-ground ligtning and surface rainfall in warm-season Florida thunderstorms, J. Geophys. Res., 111, D19203, doi:10.1029/2005JD006802, 2006.

Hlavcova, H., Kohnova, S., Kubes, R., Szolgay, J., and Zvolensky, M.: An empirical method for estimating future flood risks for flood warnings, Hydrol. Earth Syst. Sci., 9, 431-448, doi:10.5194/hess-9-431-2005, 2005.

Houze, R. A.: Stratiform precipitation in regions of convection: A meteorological paradox?, B. Am. Meteorol. Soc., 78, 2179-2196, doi:10.1175/15200477(1997)078<2179:SPIROC>2.0.CO;2, 1997.

Jensen, H., Lang, H., and Rinderknecht, J.: Extreme point rainfall of varying duration and return period 1901-1970, in: Hydrological Atlas of Switzerland, Plate 2.4.2, Federal Office for the Environment FOEN, Berne, Switzerland, 1997.

Kao, S.-C. and Govindaraju, R. S.: A bivariate frequency analysis of extreme rainfall with implications for design, J. Geophys. Res., 112, D13119, doi:10.1029/2007JD008522, 2007.

Katsanos, D., Lagouvardos, K., Kotroni, V., and Argiriou, A.: Combined analysis of rainfall and lightning data produced by mesoscale systems in the central and eastern Mediterranean, Atmos. Res., 83, 55-63, doi:10.1016/j.atmosres.2006.01.012, 2007.

Katz, R. W., Parlange, M. B., and Naveau, P.: Statistics of extremes in hydrology, Adv. Water Resour., 25, 1287-1304, doi:10.1016/S0309-1708(02)00056-8, 2002.

Kinnell, P. I. A.: Event erosivity factor and errors in erosion predictions by some empirical models, Aust. J. Soil Res., 41, 9911003, doi:10.1071/SR02123, 2003.

Kochtubajda, B., Burrows, W. R., Liu, A., and Patten, J. K.: Surface rainfall and cloud-to-ground lightning relationships in Canada, Atmos. Ocean, 51, 226-238, doi:10.1080/07055900.2013.780154, 2013.

Kotroni, V. and Lagouvardos, K.: Lightning occurrence in relation with elevation, terrain slope, and vegetation cover in the Mediterranean, J. Geophys. Res., 113, D21118, doi:10.1029/2008JD010605, 2008.

Koutroulis, A. G., Grillakis, M. G., Tsanis, I. K., Kotroni, V., and Lagouvardos, K.: Lightning activity, rainfall and flash flooding - occasional or interrelated events? A case study in the island of Crete, Nat. Hazards Earth Syst. Sci., 12, 881-891, doi:10.5194/nhess-12-881-2012, 2012.

Koutsoyiannis, D., Kozonis, D., and Manetas, A.: A mathematical framework for studying rainfall intesity-duration-frequency relationships, J. Hydrol., 206, 118-135, doi:10.1016/S00221694(98)00097-3, 1998. 
Kyselý, J., Gaál, L., Picek, J., and Schindler, M.: Return periods of the August 2010 heavy precipitation in northern Bohemia (Czech Republic) in present climate and under climate change, Journal of Water and Climate Change, 4, 265-286, doi:10.2166/wcc.2013.051, 2013.

Lang, S., Tao, W. K., Simpson, J., and Ferrier, B.: Modeling of convective-stratiform precipitation processes: Sensitivity to partitioning methods, J. Appl. Meteorol., 42, 505-527, doi:10.1175/1520-0450(2003)042<0505:MOCSPP> 2.0.CO;2, 2003.

Llasat, M. C.: An objective classification of rainfall events on the basis of their convective features: application to rainfall intensity in the Northeast of Spain, Int. J. Climatol., 21, 1385-1400, doi:10.1002/joc.692, 2001.

Llasat, M. C.: High magnitude storms and floods, in: The Physical Geography of the Mediterranean, edited by: Woodward, J. C., Oxford University Press, Oxford, 513-540, 2009.

Llasat, M. C., Rigo, T., Ceperuelo, M., and Barrera, A.: Estimation of convective precipitation: the meteorological radar versus an automatic rain gauge network, Adv. Geosci., 2, 103-109, doi:10.5194/adgeo-2-103-2005, 2005.

Llasat, M. C., Ceperuelo, M., and Rigo, T.: Rainfall regionalization on the basis of the precipitation convective features using a raingauge network and weather radar observations, Atmos. Res., 83, 415-426, doi:10.1016/j.atmosres.2005.08.014, 2007.

Lloyd, C. R.: The temporal distribution of Amazonian rainfall and its implications for forest interception, Q. J. Roy. Meteor. Soc., 116, 1487-1494, doi:10.1002/qj.49711649612, 1990.

Merz, R. and Blöschl, G.: A process typology of regional floods, Water Resour. Res., 39, 1340, doi:10.1029/2002WR001952, 2003.

Molnar, P. and Burlando, P.: Variability in the scale properties of high-resolution precipitation data in the Alpine climate of Switzerland, Water Resour. Res., 44, W10404, doi:10.1029/2007WR006142, 2008.

Overeem, A., Buishand, A., and Holleman, I.: Rainfall depthduration-frequency curves and their uncertainties, J. Hydrol., 348, 124-134, doi:10.1016/j.jhydrol.2007.09.044, 2008.

Overeem, A., Buishand, A., and Holleman, I.: Extreme rainfall analysis and estimation of depth-duration-frequency curves using weather radar, Water Resour. Res., 45, W10424, doi:10.1029/2009WR007869, 2009.

Panziera, L. and Germann, U.: The relation between airflow and orographic precipitation on the southern side of the Alps as revealed by weather radar, Q. J. Roy. Meteor. Soc., 136, 222-238, doi:10.1002/qj.544, 2010.

Paschalis, A., Molnar, P., and Burlando, P.: Temporal dependence structure in weights in a multiplicative cascade model for precipitation, Water Resour. Res., 48, W01501, doi:10.1029/2011WR010679, 2012.

Pešice, P., Sulan, J., and Řezáčová, D.: Convection precursors in the Czech territory, Atmos. Res., 67-69, 523-532, doi:10.1016/S0169-8095(03)0007, 2003.

Petersen, W. A. and Rutledge, S. A.: On the relationship between cloud-to-ground lightning and convective rainfall, J. Geophys. Res., 103, 14025-14040, doi:10.1029/97JD02064, 1998.
Pineda, N., Rigo, T., Bech, J., and Soler, X.: Lightning and precipitation relationship in summer thunderstorms: Case studies in the North Western Mediterranean region, Atmos. Res., 85, 159-170, doi:10.1016/j.atmosres.2006.12.004, 2007.

Price, C. and Federmesser, B.: Lightning-rainfall relationships in Mediterranean winter thunderstorms, Geophys. Res. Lett., 33, L07813, doi:10.1029/2005GL024794, 2006.

Price, C., Yair, Y., Mugnai, A., Lagouvardos, K., Llasat, M. C., Michaelides, S., Dayan, U., Dietrich, S., Di Paola, F., Galanti, E., Garrote, L., Harats, N., Katsanos, D., Kohn, M., Kotroni, V., Llasat-Botija, M., Lynn, B., Mediero, L., Morin, E., Nicolaides, K., Rozalis, S., Savvidou, K., and Ziv, B.: Using lightning data to better understand and predict flash floods in the Mediterranean, Surv. Geophys., 32, 733-751, doi:10.1007/s10712-011-9146-y, 2011a.

Price, C., Yair, Y., Mugnai, A., Lagouvardos, K., Llasat, M. C., Michaelides, S., Dayan, U., Dietrich, S., Galanti, E., Garrote, L., Harats, N., Katsanos, D., Kohn, M., Kotroni, V., Llasat-Botija, M., Lynng, B., Mediero, L., Morin, E., Nicolaides, K., Rozalis, S., Savvidou, K., and Ziv, B.: The FLASH Project: using lightning data to better understand and predict flash floods, Environmental Science and Policy, 14, 898-911, doi:10.1016/j.envsci.2011.03.004, 2011b.

Reinhold, F.: Regenspenden in Deutschland (Grundwerte für die Entwässerungstechnik, GE 1940), Archiv für Wasserwirtschaft, Heft Nr. 56, Reichsverband der Deutschen Wasserwirtschaft, Berlin, 1940.

Restrepo-Posada, P. J. and Eagleson, P. S.: Identification of independent rainstorms, J. Hydrol., 55, 303-319, doi:10.1016/00221694(82)90136-6, 1982.

Rigo, T. and Llasat, M. C.: A methodology for the classification of convective structures using meteorological radar: Application to heavy rainfall events on the Mediterranean coast of the Iberian Peninsula, Nat. Hazards Earth Syst. Sci., 4, 59-68, doi:10.5194/nhess-4-59-2004, 2004.

Rigo, T. and Llasat, M. C.: Analysis of mesoscale convective systems in Catalonia using meteorological radar for the period 1996-2000, Atmos. Res., 83, 458-472, doi:10.1016/j.atmosres.2005.10.016, 2007.

Rivas Soriano, L. and De Pablo, F.: Analysis of convective precipitation in the western Mediterranean Sea through the use of cloud-to-ground lightning, Atmos. Res., 66, 189-202, doi:10.1016/S0169-8095, 2003.

Rivas Soriano, L., De Pablo, F., and Garcia Diez, E.: Relationship between convective precipitation and cloud-to-ground lightning in the Iberian peninsula, Mon. Weather Rev., 129, 2998-3003, doi:10.1175/1520-0493(2001)129<2998:RBCPAC>2.0.CO;2, 2001.

Ruiz-Leo, A. M., Hernandez, E., Queralt, S., and Maqueda, G.: Convective and stratiform precipitation trends in the Spanish Mediterranean coast, Atmos. Res., 119, 46-55, doi:10.1016/j.atmosres.2011.07.019, 2013.

Rulfová, Z. and Kyselý, J.: Disaggregating convective and stratiform precipitation from station weather data, Atmos. Res., 134, 100-115, doi:10.1016/j.atmosres.2013.07.015, 2013.

Serinaldi, F.: Analysis of inter-gauge dependence by Kendall's tau, upper tail dependence coefficient, and 2-copulas with application to rainfall fields, Stoch. Env. Res. Risk A., 22, 671-688, doi:10.1007/s00477-007-0176-4, 2008. 
Schüepp, M. and Gensler, G.: Klimaregionen der Schweiz, in: Die Beobachtungsnetze der Schweizerischen Meteorologischen Anstalt, Konzept 1980, edited by: Müller, G., Arbeitsberichte der Schweizerischen Meteorologischen Anstalt Nr. 93, Anhang Ib. Zürich, 1980.

Tadesse, A. and Anagnostou, E. N.: Characterization of warm season convective systems over US in terms of cloud to ground lightning, cloud kinematics, and precipitation, Atmos. Res., 91, 3646, doi:10.1016/j.atmosres.2008.05.009, 2009.

Tapia, A., Smith, J. A., and Dixon, M.: Estimation of convective rainfall from lighnting observations, J. Appl. Meteorol., 37, 1497-1509, doi:10.1175/15200450(1998)037<1497:EOCRFL>2.0.CO;2, 1998.

Tremblay, A.: The stratiform and convective components of surface precipitation, J. Atmos. Sci., 62, 1513-1528, doi:10.1175/JAS3411.1, 2005.

Vandenberghe, S., Verhoest, N. E. C., and De Baets, B.: Fitting bivariate copulas to the dependence structure between storm characteristics: A detailed analysis based on 105 year 10 min rainfall, Water Resour. Res., 46, W01512, doi:10.1029/2009WR007857, 2010.

Velikanov, M. A.: Gidrologia suši, Gidrometeoidzat, Leningrad, 1964.

Vörösmarty, Ch. J., de Guenni, L. B., Wollheim, W. M., Pellerin, B., Bjerklie, D., Cardoso, M., D'Almeida, C., Green, P., and Colon, L.: Extreme rainfall, vulnerability and risk: a continentalscale assessment for South America, Philos. T. Roy. Soc. A, 371, 20120408, doi:10.1098/rsta.2012.0408, 2013.

Watson, P. A., Gunes, M., Potter, B. A., Sathiaseelan, V., and Leitas, D. J.: Development of a climatic map of rainfall attenuation for Europe, Final Report of the European Space Agency, ESTEC CONTR. No. 4162/79/NL, Postgraduate School of Electrical and Electronic Engineering, University of Bradford, UK, 1982.
Wilhelmi, O. V. and Morrs, R. E.: Integrated analysis of societal vulnerability in an extreme precipitation event: A Fort Collins case study, Environ. Sci. Policy, 26, 49-62, doi:10.1016/j.envsci.2012.07.005, 2013.

Winsemius, H. C., Van Beek, L. P. H., Jongman, B., Ward, P. J., and Bouwman, A.: A framework for global river flood risk assessments, Hydrol. Earth Syst. Sci., 17, 1871-1892, doi:10.5194/hess-17-1871-2013, 2013.

Wischmeier, W. H. and Smith, D. D.: Predicting rainfall erosion losses-a guide to conservation planning, Agriculture Handbook, No. 537, US Department of Agriculture, Washington, DC, 1978.

Wussow, G.: Untere Grenzwerte dichter Regenfälle, Meteorol. Z., 39, 173-178, 1922.

Yair, Y., Lynn, B., Price, C., Kotroni, V., Lagouvardos, K., Morin, E., Mugnai, A., and Llasat, M. C.: Predicting the potential for lightning activity in Mediterranean storms based on the Weather Research and Forecasting (WRF) model dynamic and microphysical fields, J. Geophys. Res., 115, D04205, doi:10.1029/2008JD010868, 2010.

Zeng, N., Shuttleworth, J. W., and Gash, J. H. C.: Influence of temporal variability of rainfall on interception loss. Part I. Point analysis, J. Hydrol., 228, 228-241, doi:10.1016/S00221694(00)00140-2, 2000.

Zimmer, M., Craig, G. C., Keil, C., and Wernli, H.: Classification of precipitation events with a convective response timescale and their forecasting characteristics, Geophys. Res. Lett., 38, L05802, doi:10.1029/2010GL046199, 2011. 